\title{
A Concept of Decision Making in Land Productivity: Combining Highest \& Best Use and Analytic Network Process
}

\author{
Urifatul Azizah $^{1}$, Christiono Utomo ${ }^{1}$
}

\begin{abstract}
Understanding the concept of using the highest and best market is essential. Market forces will determine the creation of market value. To reach the equilibrium point, what the stakeholder wants is their desire is accep and provide optimal satisfaction (utility). To develop into a commercial property area it is necessary to analyse the most feasible and permitted land use permits, financially feasible and highest land productivity. Highest and best use (HBU) with feasibility requires interrelated criteria, therefore data and indirect consideration are required in additional research. Analytic Network Process (ANP) is a decision-making problem. It cannot be structured hierarchically because it leads to interaction and determines a higher level in the lower element. Not only are criteria that define alternatives as in hierarchy, but this is also an alternative can be important by using Analytic Network Process (ANP). This Paper is a conceptual based on literature review. A set of previous research are analysis to get the synthesis of the highest and best use (HBU) and the analytic network process (ANP) on land productivity decision making. A model is resulted to present the combination of four criteria of $\mathrm{HBU}$ into ANP.
\end{abstract}

Keywords-Analytic Network Proces, Highest and Best Use, Land Productivity.

\section{INTRODUCTION}

Understanding the meaning of market is very important for the concept of highest and best use[1]. This is a market power that creates value, so the interaction between market power and the highest and best use is a sensitive and important thing. the highest and best use analysis aims to identify the most advantageous and competitive allocation of the observed land.

The current ground value is relatively low when compared to the initial construction. The value of traditional land is lower when compared to the surrounding buildings. Due to the development of areas associated with land values, high land values will encourage the use of land that has higher economic aspects, allowing productivity that can be applied to the value of land.

According to [2] on the assessment process, the highest and best use is usually done before using the application of the three assessment methods. However, in the assessment assignment, the final test of financial feasibility and maximum productivity can only be obtained from the application and development of the three approaches. The

\footnotetext{
${ }^{1}$ Urifatul Azizah and Christiono Utomo are with Department of Civil Engineering, Institut Teknologi Sepuluh Nopember, Surabaya, 60111, Indonesia. E-mail: azizahurifatul@gmail.com; christiono@ce.its.ac.id.
}

highest and best use approach which is called as the highest and best use criterion is legally permitted, physically possible, financially feasible, and produces maximally. All of these approaches are often considered consecutively.

Through analysis of HBU, it will be obtained several alternatives. From the previous studies, the selected alternatives has been derived from the maximum productivity value so, it is beneficial for some stakeholders only. Cheng [3] explained that in purpose to get the most productive of accurate land, it is necessary to use the decision along with the needs of its stakeholders derived from Analytic Network Process (ANP).

HBU has 4 interconnected criterias, while ANP has interrelated elements. Therefore, HBU and ANP have similarities to be applied in this study. This study aims to determine the relationship between HBU utilization of land and uses the ANP to support the achievement of maximum productivity of land in accordance with the wishes of stakeholders.

\section{METHOD}

This Paper is a conceptual based on literature review. A set of previous research had been analyzed to get the synthesis of the highest and best use (HBU) and the analytic network process (ANP) on land productivity decision making. A model is resulted to present the combination of four criteria of HBU into ANP.

This section will explain some of the theories that will be used as a basic understanding in this research. Understanding will include property valuation, HBU concepts, and ANP concepts.

Herjanto and Hidayati [1] said that the assessment of this property can be interpreted as a combination of science that consist of natural and art, which has the purpose to estimate the value of an interest contained in the property so it can be achieved certain goals and at the time that has been set and take into account all the characteristics that exist in the property including the types of existing investments.

The principles and basics of the assessment according to [4] are: Principle of the highest and best use, Principle of supply and demand, Principle of substitution, Principle of anticipation, Principle of change, Principle of conformity, Principle of competition, and Principle of increasing and decreasing return.

HBU is a concept directed by market powers. Which is creates the value, so the interaction between market powers 
and the highest and best use is a sensitive and important thing[2]. The Land in the analysis of Highest and Best Use is divided into 3; empty land, land that is considered empty, and property under development.

To determine the HBU it should be through a testing process involving 4 criteria with their respective requirements based on the Indonesian assessment standards. These criteria are: Legally, Physically, Financially, and Maximum productivity. The use of $4 \mathrm{HBU}$ criteria has been used by previous research as in Table 1 . Since 1994, [5] in USA Analyze the HBU used those 4 criterias. While in Indonesia, [1] in 2003 also used the same 4 criterias to analyze the HBU.

The Analytic Network Process (ANP) is a new approach of qualitative methods which is the development of the Analytic Hierarchy Process (AHP) method. The advantage of ANP is its simple decision-making methods that can be used in complex problems[6].

After getting the questionnaire, the stage moves to these following stages; Arranging the problem structures and developing the linkage models, forming pairwise comparison matrices, Calculating the element weights, Calculating the consistency ratio, the value of CI is meaningless if there is a standard indicating that CI represents a consistent matrix, and creating supermatrix with unweighted supermatrix, weighted supermatrix, and stage limiting supermatrix.

Based on the previous research in Table 2, there are some basic equations indicating that this research aims to get the best investment decisions and to provide maximum productivity while considering the prevailing regulations. In 2005, [3] succeeded in using ANP as an effective tool to get the highest alternative location. and in 2009, [7] used ANP to find a positive relationship between team skills and team performance. While [8] in 2009 also usede the ANP to obtain best co-design. In 2017, [9] in decision of making $\mathrm{HBU}$, used the Connecting functions and costs to get an alternative solution value.

\section{RESUltS AND DisCUSSION}

Criteria in the analysis Highest and best use is legally permitted, physically possible, financially feasible, and produces maximally. These criterias are often considered consecutively. An analysis that legally and physically permitted would be possible before financial feasibility analysis and produce maximally.

The use may be financially feasible yet if it has a legal prohibition and physical rejection, it could be impossible to realize. But if there is a possibility that rationally can and has been previously known, an unacceptable situation Will be changed to vice versa so it is feasible to use HBU.

In the legally permitted criteria, all cases should be determined what is not legally permitted by law. private restrictions, zoning, building-related provisions, historical building requirements, and regulations on AMDAL should be assessed as they may be a barrier to many potential uses. Researchers must understand the environmental requirements related to clean water, clean air, and soil moisture as well, and they should be sensitive to community reactions toward development proposals.

The use of the highest and best use also depends on physical considerations such as size, design, and condition. If the property should be changed for use in other uses, the cost of conversion should be assessed based on the rate of return provided by the new usage. then it is clear that the cost of the change depends on the physical condition of the property.

To determine financially feasible a property used as a potential income producing property, compared to the value of benefits or benefits obtained by expenditures. If the value of benefits or the benefits itself is bigger than the expenditure, then the use is considered feasible to be considered. And vice versa.

The potential use of HBU of land is for the long term to remain in the normal life-span of development. Expectation of the normal life of development depends on the type of building, quality of construction, and other factors. The benefit or income stream generated from the building reflects a careful and usually very specific consideration.

From the explanation above, the criteria of HBU cannot be randomized or reduced its use. Since, all the HBU criterias of its use are sequentially and complexly interconnected, it may not be so easy to classify elements by leveling as in the hierarchy. Because of the need for feedback and for the inner dependence loop and thus ANP can represent the network appropriately, where there is dependence on the upper level element to the lower level which is structured as hierarchy. so, it can be seen in Figure 1.

From Figure 1, obtained that HBU analysis has been done in sequence to obtain some alternatives per maximum productivity that still not necessarily based on the stakeholder wishes that is inside in red box. So, it was necessary to do further research to determine the alternative using ANP analysis, where the existing alternative would be returned to stakeholders to be selected for the value of interest. ANP stages used in blue squares. After the ANP stage was completed it would be obtained alternative which is compatible with the needs of the stakeholders.

This study used objects in the form of traditional markets in cities where alternative traditional market development can be in the form of:

1) Market revitalization

2) Market revitalization which can be in the form of a modern shopping center.

3) Mix used market with hotel

4) Mix used markets with hotels in the form of hotels with classic concepts.

5) Mix used market with offices

6) Mix used markets with offices are needed because the market locations are in urban centers.

The network structure serves to determine the influence or interdependence between elements, In this study there are 7 clusters, namely legal, physical, financial, maximum productivity, market revitalization, mix used markets with 
hotels, and mix used markets with offices. The network structure in the following Figure 2.

From the 7 clusters, the relationship between the criteria of HBU was conducted to determine how strong the interrelationships were. Obtained results using the DEMATEL method as in the following Table 3.

From these results, law only affects other criteria (oneway relationships). While the maximum physical, financial, and productivity criteria are correlated (two-way relationship). The form of the relationship can be in the following Table 4.

The HBU method is said to be objective at the legal level only. Whereas the ANP-HBU method is said to be more objective because all respondents are independent, do not have the pressure from the highest position or are not dominated, so the respondents can reflect the results.

The results using the HBU method alone without a combination with ANP are obtained as an alternative mix used market with the hotel. Whereas from the results using the ANP-HBU method in the form of an alternative market revitalization. From the results of these two methods it produces a different ending. Because the HBU method will depend on financial analysis. While for the ANP-HBU method to get the results of decision making that are in accordance with the needs of stakeholders that influence the traditional urban market land. Where influential stakeholders are respondents from this study.

\section{CONCLUSION}

The alternative determination of HBU can be combined with the ANP method because of its sequential and complex use, so that ANP can represent the network that meet the expectation of stakeholders. Future research is necessary for field cases and group decisions to represent all stakeholders.

\section{ACKNOWLEDGMENT}

The authors appreciate the recognition and awards in forms of research grant and a fellowship from "Penelitian Unggulan Perguruan Tinggi (PUPT) 2018 based on contract number 869/PKS/ITS/2018”.

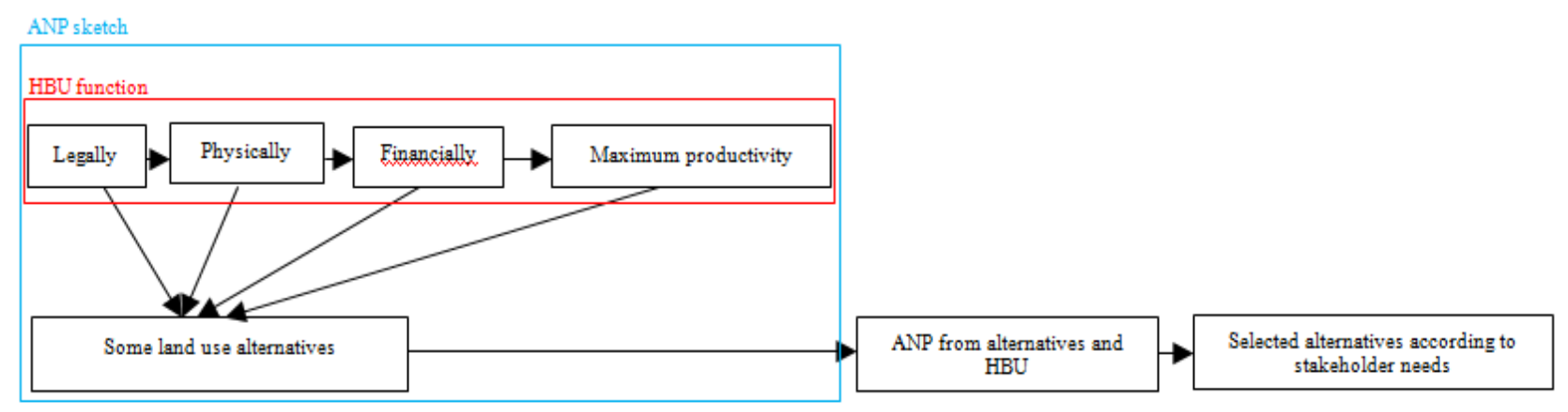

Figure 1. Concept of research model. Below the figure.

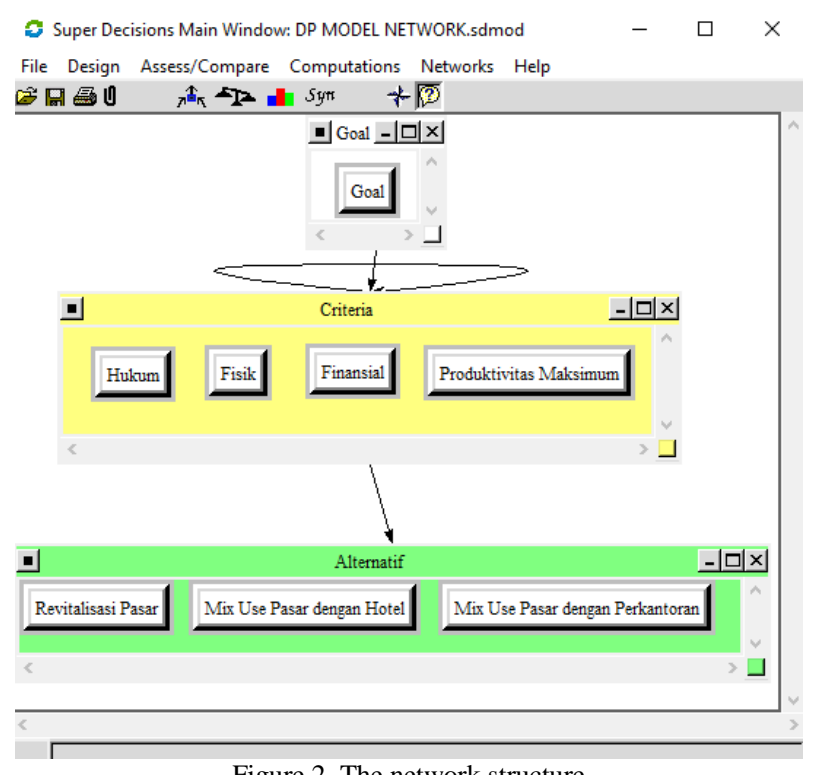

Figure 2. The network structure
TABLE 1.

CRITERIA USED BY PREVIOUS RESEARCH

\begin{tabular}{|c|c|c|c|c|}
\hline Researchers & Legally & Physically & Fanancially & $\begin{array}{c}\text { Maximum } \\
\text { Productivity }\end{array}$ \\
\hline $\begin{array}{l}\text { Fanning and } \\
\text { Pearson[5] }\end{array}$ & $\mathrm{v}$ & $\mathrm{v}$ & $\mathrm{V}$ & $\mathrm{v}$ \\
\hline Elly[10] & $\mathrm{v}$ & $\mathrm{v}$ & $\mathrm{v}$ & $\mathrm{v}$ \\
\hline $\begin{array}{l}\text { Harijanto } \\
\text { and Hidayati } \\
{[1]}\end{array}$ & $\mathrm{v}$ & $\mathrm{v}$ & $\mathrm{v}$ & $\mathrm{v}$ \\
\hline $\begin{array}{l}\text { Rettermanh } \\
\text { [11] }\end{array}$ & $\mathrm{v}$ & $\mathrm{v}$ & $\mathrm{v}$ & $\mathrm{v}$ \\
\hline Fanning[12] & $\mathrm{v}$ & $\mathrm{v}$ & $\mathrm{v}$ & $\mathrm{v}$ \\
\hline
\end{tabular}


TABLE 2.

PREVIOUS RESEARCH HAS BEEN DONE IN RELATION TO THEME OF HBU ANS ANP RESEARCH

\begin{tabular}{ll}
\hline \hline \multicolumn{1}{c}{ Problems } & Result \\
\hline $\begin{array}{l}\text { Limited land use to find alternative where good location to build shopping center } \\
\text { with highest land value by using ANP[3]. }\end{array}$ & ANP is an effective tool. \\
Teams must be evaluated and tracked to optimize team performance[7]. & $\begin{array}{l}\text { Result of the ANP found no positive relationship between team } \\
\text { skill and team performance. }\end{array}$ \\
$\begin{array}{l}\text { ANP is a general theory of relative measurement of the individual ratios that } \\
\text { represent the relative influence of factors that interact with the control criteria[8]. } \\
\begin{array}{l}\text { Complex problems into hierarchical structures with dependencies and feedback } \\
\text { systems[13]. }\end{array}\end{array}$ & $\begin{array}{l}\text { ANP is used as a troubleshooting tool because in AHP there is } \\
\text { nalue-based decision-making for HBU consists of value-based processes and multi- } \\
\text { criteria decision making processes[9]. }\end{array}$ \\
\hline \hline
\end{tabular}

TABLE 4.

THE VALUE OF INTERRELATIONSHIPS BETWEEN CRITERIA

\begin{tabular}{ccc}
\hline \hline Number & Criteria & The Form of Linkage of Elements \\
\hline 1 & $\begin{array}{c}\text { Legally } \\
\text { Physically }\end{array}$ & The law will affect the physical structure in terms of size and shape. \\
\hline 2 & Legally & Land use law will affect how much investment. \\
\hline 3 & Financially & Urban zoning systems will affect the productivity of the land. \\
\hline 4 & Physically & Calculation of land area and various supporting needs correlates with financial needs. \\
\hline 5 & Financially & Physically \\
\hline \hline
\end{tabular}

TABLE 3.

RELATION MATRIX

\begin{tabular}{ccccc}
\hline \hline & Criteria 1 (C1) & Criteria 2 (C2) & Criteria 3 (C3) & Criteria 4 (C4) \\
\cline { 2 - 5 } & Legally & Physically & Financially & Maximum Productivity \\
\hline C1 & Not Related & Not Related & Not Related & Not Related \\
C2 & Not Related & Related & Related & Related \\
C3 & Not Related & Related & Related & Related \\
C4 & Not Related & Related & Related & Not Related \\
\hline \hline
\end{tabular}

\section{REFERENCES}

[1] B. Harjanto and W. Hidayati, Konsep Dasar Penilaian Properti, 2nd ed. Yogyakarta: BPFE, 2014.

[2] A. Prawoto, Teori dan praktek penilaian properti, 3rd ed. Yogyakarta: BPEF, 2015.

[3] E. W. L. Cheng, H. Li, and L. Yu, "The analytic network process (ANP) approach to location selection: a shopping mall illustration Article information,” Constr. Innov., vol. 5, no. 2, pp. 83-97, 2005.

[4] U. Hamdan and A. Wijaya, "Analisa komparatif resiko keuangan Bank Perkreditan Rakyat (BPR) konvensional dan BPR Syariah,” J. Manejemen Bisnis Sriwij., vol. 4, no. 7, pp. 1-18, 2006.

[5] S. F. Fanning, T. V. Grissom, and T. D. Pearson, Market analysis for valuation appraisals. Chicago, Illinois: Appraisal Institute, 1994.

[6] L. Saaty and L.G. Vargas, Decision Making with the Analytic Network Process. New York: Springer, 2008.

[7] E. W. L. Cheng, "Performance evaluation of high-performing IS project teams: An analytic network process approach,” in 2009 IEEE International Conference on Industrial Engineering and Engineering Management, 2009, pp. 1612-1616.
[8] C.-W. Chang, C.-R. Wu, and C.-C. Chen, "Analytic network process decision-making to assess collaborative design systems organizational performance," in 2009 Fourth International Conference on Innovative Computing, Information and Control (ICICIC), 2009, pp. 1264-1267.

[9] Y. Rahmawati and C. Utomo, "Value-based decision for highest and best use," in 2017 International Conference on Engineering Technology and Technopreneurship (ICE2T), 2017, pp. 1-5.

[10] R. M. Betts and S. J. Ely, Basic real estate appraisal, 5th ed. Cincinnati Ohio: Prentice Hall, 2001.

[11] M. Rattermann, The student handbook to the appraisal of real estate. Chicago: Appraisal Institute, 2004.

[12] S. F. Fanning, Market analysis for real estate: concepts and applications in valuation and highest and best use. Chicago IL: Appraisal Institute, 2005.

[13] M. Ayub, M. J. Kabir, and M. G. R. Alam, "Personnel selection method using Analytic Network Process (ANP) and fuzzy concept," in 2009 12th International Conference on Computers and Information Technology, 2009, pp. 373-378. 